portions of the text are arranged on opposite pages, and corresponding paragraphs represent close translations one of the other. Literary style has been subordinated to the necessity for maintaining as nearly literal a relationship as possible between the English and German texts. Four appendices deal with abbreviations used in geological literature, English and German weights and measures, the ehemical elements, and mineral names.

As a general criticism it may be suggested that the text is somewhat unbalanced with regard to the amount of space allotted to each of the several branches of geology. Thus, palæontology is represented solely by a chapter containing formal descriptions of the various groups of invertebrate fossils, while vertebrate palæontology and palæobotany are ignored. The principles of stratigraphy are dismissed in a single page. On the other hand, petrology, mineralogy, crystallography and allied subjects receive detailed treatment.

Some terms one would expect to have been included have been omitted, and a few spelling errors were noticed. As a whole the book can be recommended for the use of students. A mastery of its contents should adequately if not completely equip those who wish to read geological literature in the original German.

V. A. E.

A Key to Mineral Groups, Species and Varieties. By Dr. E.S. Simpson. Pp. viii +84 . (London: Chapman and Hall, Ltd., 1932.) 10s. 6d. net.

IT has always seemed a matter for regret that so many of the names applied to mineral species, even in recent years, give no indication whatever of the chemical composition or physical properties of the mineral. Instead of attempting to clarify the science by devising a self-explanatory system of nomenclature, mineralogists continue to increase the tax on their memories by attaching to new minerals quite irrational names. This being the case, Dr. Simpson justifiably claims that his tables may be regarded as a vade mecum to everyone interested in minerals. He has listed in alphabetical order upwards of 1800 mineral names. Opposite each mineral is stated concisely its chemical composition, specific gravity, crystal system and refractive indices. These data have been collected from the latest and most accurate sources available. In addition, reference is given in every case to a source of detailed information regarding each mineral. The latter item is particularly valuable in the case of the newer mineral species, about which data have, until now, remained scattered through many publications.

The literature of mineralogy is cumbered with a great number of useless names. The list is selective to the extent that the author has omitted names which he regards as obsolescent or which stand only for minute differences in unessential characteristics.

The tables represent a careful compilation by the author of information gathered from many sources over a long period of years. Dr. Simpson is to be congratulated on having made accessible to the public in such concise form the result of his labours.

The Microscopic Characters of Artificial Inorganic Solid Substances or Artificial Minerals. By Prof. A. N. Winchell. With a Chapter on the Universal Stage, by Prof. R. C. Emmons. Second edition. Pp. xvii +403 . (New York: John Wiley and Sons, Inc. ; London: Chapman and Hall, Ltd., 1931.) 31s. net.

FormerLy known as "The Optic and Microscopic Characters of Artificial Minerals", the modification in the title of the new edition of this work serv's to prevent misapprehension as to its scope. This is, in fact, much wider than would be the case if it dealt only with synthetic minerals, using the latter term in its generally accepted sense. The author has attempted to include all inorganic substances the optical constants of which are known.

Many changes have been made since the first edition appeared (NATURE, vol. 122, p. 436, 1928). The book is now cloth bound, and has been greatly enlarged, chiefly through the introduction of a new section on optical principles and the methods of study of crystals under the microscope. This, Part I of the new edition, consists largely of revised selections from the same author's "Elements of Optical Mineralogy", Part I, third edition (see Nature, vol. 123, p. 158, 1929), and includes a chapter on the universal stage. Numerous alterations and additions have been made in the descriptive section of the book, and the determinative tables have been re-written and rearranged.

The new section obviates the necessity for reference to other textbooks for those not familiar with the microscopic study of crystals and renders the book to a large extent self-contained. Altogether the new edition is a great improvement on the old.

\section{Mathematical and Physical Science}

Dielectric Constant and Molecular Structure. By Prof. C. P. Smyth. (American Chemical Society Monograph Series, No. 55.) Pp. 214. (New York: The Chemical Catalog Co. Inc., 1931.) 4 dollars.

THIs book effectively completes Debye's "Polar Molecules" and Errera's "Polarisation Diélectrique" by a detailed account of the subject in its relation to chemical constitution. Electrically polar molecules, its principal concern, have never been of so much importance in physics as the formally similar magnetic dipoles or as non-polar molecules, but the advent of thermionic valve methods for finding the dielectric constant opened up a wide field for their application in chemistry, development of which is due in no small degree to Prof. Smyth.

The subject matter falls roughly under three heads. The first three chapters are upon the elementary theory and the measurement of the 